\title{
Comparative risk of gastrointestinal bleeding with dabigatran, rivaroxaban, and warfarin: population based cohort study
}

\author{
Neena S Abraham, ${ }^{123}$ Sonal Singh, ${ }^{45}$ G Caleb Alexander, ${ }^{45}$ Herbert Heien, ${ }^{3}$ Lindsey R Haas, ${ }^{3}$ \\ William Crown, ${ }^{6}$ Nilay D Shah ${ }^{23}$
}

'Division of Gastroenterology and Hepatology, Department of Medicine, Mayo Clinic, 13400 East Shea Boulevard,

Scottsdale, AZ, 85259, USA

2Division of Health Care Policy and Research, Department of Health Services Research, Mayo Clinic, Rochester, MN, USA

${ }^{3}$ Mayo Clinic Robert D and Patricia E Kern Center for the Science of Health Care Delivery, Rochester, MN, USA

${ }^{4}$ Division of General Internal Medicine, Johns Hopkins School of Medicine, Baltimore, MD, USA

5Department of Epidemiology, Johns Hopkins Bloomberg School of Public Health and Center for Drug Safety and Effectiveness, Baltimore, MD, USA

${ }^{6}$ Optum Labs, Cambridge, MA USA

Correspondence to:

N S Abraham

abraham.neena@mayo.edu Additional material is published online only. To view please visit the journal online (http:// dx.doi.org/10.1136/bmj.h1857)

Cite this as: BMJ 2015;350:h1857 doi: 10.1136/bmj.h1857

Accepted: 23 March 2015

\section{ABSTRACT}

OBJECTIVE

To determine the real world risk of gastrointestinal bleeding associated with the use of the novel oral anticoagulants dabigatran and rivaroxaban compared with warfarin.

\section{DESIGN}

Retrospective, propensity matched cohort study.

SETTING:

Optum Labs Data Warehouse, a large database including administrative claims data on privately insured and Medicare Advantage enrollees.

\section{PARTICIPANTS}

New users of dabigatran, rivaroxaban, and warfarin from 1 November 2010 to 30 September 2013.

\section{MAIN OUTCOME MEASURES}

Incidence rates (events/100 patient years) and propensity score matched Cox proportional hazards models were used to estimate rates of total gastrointestinal bleeds, upper gastrointestinal bleeds, and lower gastrointestinal bleeds for the novel oral anticoagulants compared with warfarin in patients with and without atrial fibrillation. Heterogeneity of treatment effect related to age was examined using a marginal effects model.

\section{RESULTS}

The incidence of gastrointestinal bleeding associated with dabigatran was 2.29 (95\% confidence interval 1.88 to 2.79 ) per 100 patient years and that associated with warfarin was 2.87 (2.41 to 3.41) per 100 patient years in patients with atrial fibrillation. In non-atrial fibrillation patients, the incidence of gastrointestinal bleeding was 4.10 (2.47 to 6.80) per 100 patient years with dabigatran and 3.71 (2.16 to 6.40) per 100 patient years with warfarin. With rivaroxaban, 2.84 (2.30 to 3.52) gastrointestinal bleeding events per 100 patient years occurred in atrial fibrillation patients (warfarin 3.06 (2.49 to 3.77 )/100 patient years) and 1.66 (1.23 to 2.24$)$

\section{WHAT IS ALREADY KNOWN ON THE TOPIC}

Meta-analyses of randomized trials examining gastrointestinal bleeding rates for dabigatran and rivaroxaban, compared with warfarin, have identified higher rates of bleeds for the novel oral anticoagulants

Very little real world assessment of the safety of novel oral anticoagulants has been reported, other than in the Medicare population prescribed dabigatran

\section{WHAT THIS STUDY ADDS}

Patients younger than age of 65 have fewer gastrointestinal bleeding events when treated with novel anticoagulants compared with warfarin

However, the risk of gastrointestinal bleeding increases over the age of 65 and is particularly concerning for people aged over 75 years

per 100 patient years in non-atrial fibrillation patients (warfarin 1.57 (1.25 to 1.99)/100 patient years). In propensity score matched models, the risk of gastrointestinal bleeding with novel oral anticoagulants was similar to that with warfarin in atrial fibrillation patients (dabigatran $v$ warfarin, hazard ratio 0.79 (0.61 to 1.03); rivaroxaban $v$ warfarin, 0.93 (0.69 to 1.25)) and in non-AF patients (dabigatran $v$ warfarin, hazard ratio 1.14 (0.54 to 2.39); rivaroxaban $v$ warfarin, 0.89 (0.60 to 1.32)). The risk of gastrointestinal bleeding increased after age 65, such that by age 76 the risk exceeded that with warfarin among atrial fibrillation patients taking dabigatran (hazard ratio 2.49 (1.61 to 3.83)) and patients with and without atrial fibrillation taking rivaroxaban (2.91 (1.65 to 4.81 ) and 4.58 (2.40 to 8.72), respectively).

\section{CONCLUSIONS:}

The risk of gastrointestinal bleeding related to novel oral anticoagulants was similar to that for warfarin. Caution should be used when prescribing novel oral anticoagulants to older people, particularly those over 75 years of age.

\section{Introduction}

Atrial fibrillation is a major cause of stroke related disability and death, ${ }^{12}$ affecting 33.5 million people worldwide. $^{3}$ In the United States, $1 \%$ of the general population and $9 \%$ of people aged 80 years or over have atrial fibrillation, ${ }^{14}$ and treatment of atrial fibrillation related morbidity costs $\$ 26 \mathrm{bn}$ ( $€ 17 \mathrm{bn}$; $€ 24 \mathrm{bn}$ ) a year. ${ }^{3}$ Anticoagulation with warfarin has been shown to decrease the risk of ischemic stroke and systemic embolism in this population. ${ }^{5}$ The availability of novel oral anticoagulants has provided patients with a convenient, fixed dosed alternative to warfarin. ${ }^{6} 7$ Novel oral anticoagulants have shown non-inferiority to warfarin for the prevention of stroke and systemic embolism, with reduction in the risk of intracerebral hemorrhage. ${ }^{8}$ However, these same trials show an unexpected increase in gastrointestinal bleeding, ${ }^{89}$ especially among patients aged 75 years or over. ${ }^{10}$ Prevalence of both atrial fibrillation and gastrointestinal bleeding increases with age, ${ }^{16}$ and increased risk of gastrointestinal bleeding has been observed in older people when warfarin or novel oral anticoagulants are prescribed concomitantly with antiplatelet agents. ${ }^{9} 1112$

The magnitude of risk associated with prescription of novel oral anticoagulants remains unclear in a real world clinical setting. A recent meta-analysis of 71684 patients from four phase III randomized trials of novel oral anticoagulants highlighted a 25\% increase in gastrointestinal bleeding associated with these agents compared with warfarin. However, significant heterogeneity existed 
among trials, suggesting that the results may not be an accurate estimate of the magnitude of the risk of gastrointestinal bleeding. ${ }^{8}$ This is best shown in the ROCKET-AF trial, in which regional differences in baseline characteristics (for example, older age, history of gastrointestinal bleeding, anemia) were found to significantly affect the risk of gastrointestinal bleeding associated with rivaroxaban. ${ }^{13}$ We quantified the risk of total, upper, and lower gastrointestinal bleeding associated with dabigatran and rivaroxaban and compared these risks with those for warfarin in a geographically diverse adult population with commercial insurance in the United States.

\section{Methods}

Data source

We did a retrospective analysis of medical and pharmacy administrative claims from a large database, Optum Labs Data Warehouse, which includes privately insured people and some Medicare Advantage enrollees throughout the United States. ${ }^{14}$ The database contains data on more than 100 million enrollees, from geographically diverse regions across the United States, with greatest representation from the South and Midwest. The plan provides fully insured coverage for inpatient, outpatient, and pharmacy services. Medical claims include ICD9-CM (international classification of diseases, 9th revision, clinical modification) diagnosis codes; ICD-9 procedure codes; Current Procedural Terminology, version 4 (CPT-4) procedure codes; Healthcare Common Procedure Coding System (HCPCS) procedure codes; site of service codes; and provider specialty codes.

\section{Patient involvement and identification}

There was no patient involvement in this study. We identified all people aged 18 years or older by their index prescription of dabigatran, rivaroxaban, or warfarin. We excluded patients prescribed apixaban owing to the small sample size. We classified patients into dabigatran, rivaroxaban, or warfarin cohorts on the basis of their first filled prescription, or index date, between 1 November 2010 and 30 September 2013. We excluded patients with any previously dispensed prescription for warfarin, dabigatran, or rivaroxaban during the 12 months before the index date, as well as those who did not have continuous enrolment in a medical and pharmacy plan for 12 months before this date. We also excluded patients with mechanical heart valve or diagnosed mitral stenosis, chronic hemodialysis or peritoneal dialysis, and kidney transplant, as well as those residing in a skilled nursing facility or nursing home at the time of the index date. We categorized patients by diagnosis of atrial fibrillation, on the basis of ICD-9-CM codes (ICD-9-CM 427.31) in the primary or secondary position from any practice setting (inpatient or outpatient) during the 12 months before their index date, and we did separate analyses for the "atrial fibrillation" and "non-atrial fibrillation" cohorts.

\section{Exposures and primary outcome}

The exposures of interest were dabigatran, rivaroxaban, and warfarin. We considered patients as being continuously exposed from the index date for the duration of their prescription until a gap of 30 days occurred or until occurrence of gastrointestinal bleeding, disenrollment from the healthcare plan, or termination of treatment as defined by the absence of a new prescription by the end of the 45 day period from the last identified index medication fill. The last date of follow-up was 31 December 2013.

The primary outcome was the occurrence of a gastrointestinal bleed as defined using the Food and Drug Administration's Mini-Sentinel post-marketing surveillance system (www.mini-sentinel.org) diagnostic codes (ICD-9-CM codes used to define these outcome are listed in supplemental table A1 in the web appendix). We identified gastrointestinal bleeding by using inpatient hospital claims for relevant primary and secondary discharge diagnoses indicative of bleeding in the gastrointestinal tract.

\section{Variables of interest}

Independent variables of interest included baseline demographics (age, sex, and race/ethnicity), comorbidities, and pharmacologic risk factors for gastrointestinal bleeding. Pharmacologic factors assessed included known inducers and inhibitors of warfarin (see table A2 in appendix) and concomitant prescription of antiplatelet agents, non-steroidal anti-inflammatory drugs, selective serotonin reuptake inhibitors, proton pump inhibitors, and glucocorticoids. We identified comorbid conditions by ICD-9-CM codes in the primary or secondary position on any claim during the baseline period and included myocardial infarction, congestive heart failure, coronary bypass graft and percutaneous coronary intervention, diabetes, history of previous gastrointestinal bleed, diverticulosis, Helicobacter pylori infection, and renal disease. We used the Charlson-Deyo comorbidity index to assess patients' overall baseline comorbidity burden. ${ }^{15}$ We derived a $\mathrm{CHADS}_{2}$ score for each atrial fibrillation patient by assigning 1 point each for age 75 years or older, hypertension, diabetes mellitus, and heart failure and 2 points for previous stroke or transient ischemic attack, with a possible total score of 6 points. We defined the components of the $\mathrm{CHADS}_{2}$ score by using diagnoses coded within the 12 month baseline period before the index date. ${ }^{16}$ Similarly, we defined a modified HAS-BLED score for each patient by assigning 1 point and summing across the following conditions: hypertension, renal disease, cirrhosis, stroke, major bleeding event, age 65 and older, non-steroidal anti-inflammatory drug, antiplatelet agents, and alcohol use. ${ }^{17}$ Our dataset did not include laboratory parameters, so we were not able to assess a labile international normalized ratio (in therapeutic range $<60 \%$ of the time) in the HAS-BLED score.

\section{Statistical analysis}

We examined the effect of dabigatran, rivaroxaban, and warfarin on the risk of gastrointestinal bleeding. To do so, we used one to one propensity score matching without replacement in two separate models to adjust for differences in baseline covariates between patients 
exposed to dabigatran (versus warfarin) and rivaroxaban (versus warfarin). For each comparison, the propensity score algorithm was run separately for atrial fibrillation and non-atrial fibrillation cohorts to further lessen treatment selection differences. The propensity score model included risk factors for gastrointestinal bleeding, race, age categories (18-64, 65-75, $\geq 76$ years), and drug classes and controlled for follow-up times that may differ between the novel anticoagulant agents and warfarin by including a categorical variable representing the quarter in which the anticoagulant was started. We did a paired $t$ test for continuous variables, a McNemar test for dichotomous variables, and a Bowker's test for categorical variables with more than two levels. We considered the standardized difference of each covariate in the propensity score model. We considered variables to be significantly different after propensity score matching if the $\mathrm{P}$ value was less than 0.05 ; these variables were included as independent covariates in final multivariable models for assessment of the outcomes of interest.

We used multivariate Cox proportional hazards models to identify the associations between dabigatran and rivaroxaban and gastrointestinal bleeding. The comparator group for each exposure of interest was a propensity score matched group of patients prescribed warfarin. We considered patients with and without atrial fibrillation in separate models. We calculated the hazard ratio and 95\% confidence intervals for each outcome of interest and considered the interaction term of how the treatment effect changed as the strata of age increased in our population. To measure the risk of gastrointestinal bleeding associated with advancing age, we considered marginal effects to estimate the hazard

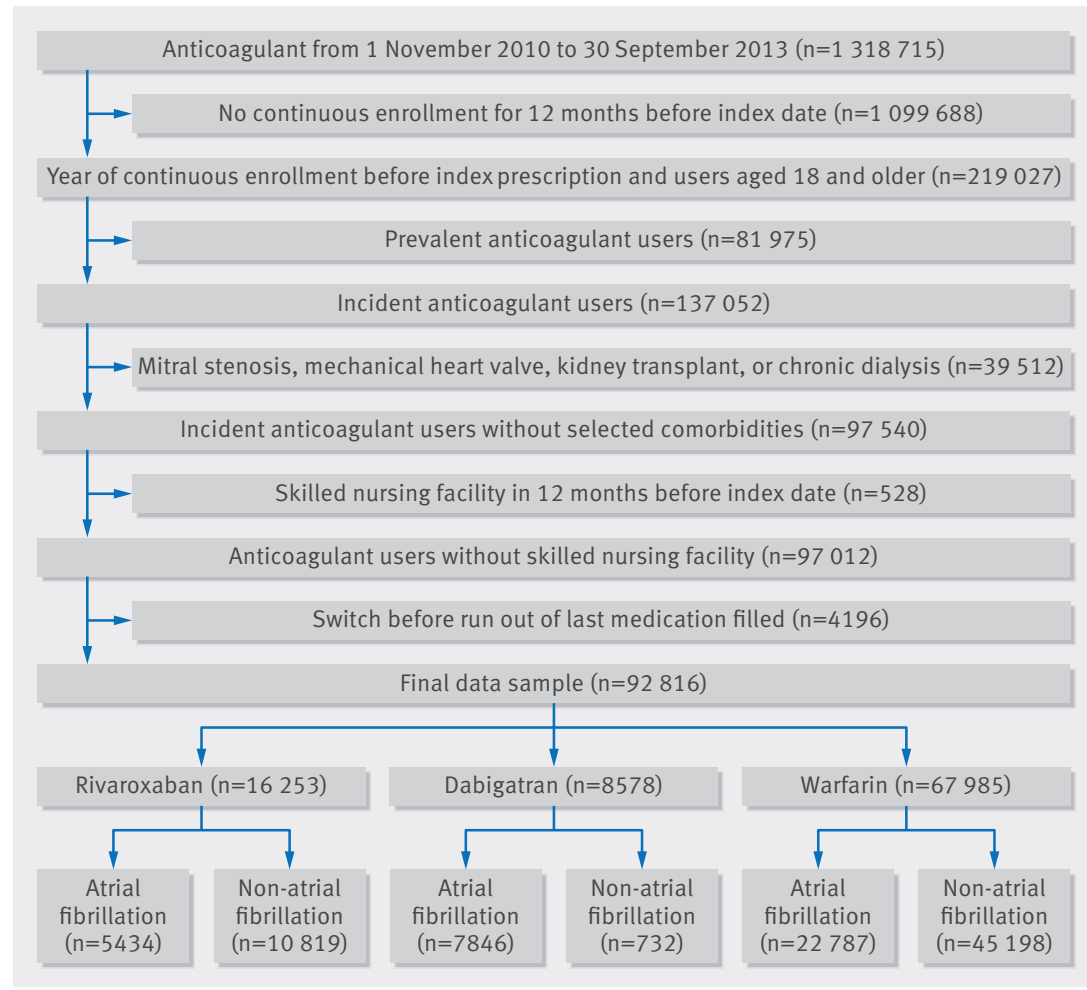

Fig 1 | Flow chart of study ratio at the given levels of the interaction, using the warfarin 18-64 age group as the control. The adjusted predictions refer to the hazard ratio of the outcome of interest (gastrointestinal bleeding), with control for other independent covariates. We calculated marginal effects as the difference between the predicted values of hazard ratio between each treatment and age group. We created the analytic dataset in SAS 9.3 and used Stata SE software (version 13.0) for the statistical analysis.

\section{Results}

\section{Patients' characteristics}

We identified 219027 continuously enrolled patients as users of anticoagulants between 1 November 2010 and 30 September 2013. Thirty seven per cent $(n=81975)$ were prevalent anticoagulant users and were excluded from the study. We excluded $29 \%(n=40040)$ who presented with mitral stenosis, mechanical heart valve, kidney transplant, chronic dialysis, or skilled nursing facility stay in the 12 months before the index date. We excluded 4\% owing to a switch in drug before their last medication fill ran out. Our final cohort of 92816 patients taking anticoagulants during our study period included $8578(9.2 \%)$ patients on dabigatran, $16253(17.5 \%)$ on rivaroxaban, and $67985(73.2 \%)$ on warfarin (fig 1).

\section{Risk of gastrointestinal bleeding with dabigatran compared with warfarin}

To create the atrial fibrillation cohort, we matched $98.8 \%$ of the dabigatran patients to $34.0 \%$ of the warfarin patients to create 7749 matched pairs. To create the non-atrial fibrillation cohort, we matched $100 \%$ of nonatrial fibrillation patients prescribed dabigatran to $1.6 \%$ of the warfarin patients to create 732 matched pairs. We compared patients' demographics and clinical characteristics between dabigatran and warfarin cohorts, and the baseline characteristics were not statistically different (tables 1 and 2).

Table 3 shows the incidence rates for total, upper, and lower gastrointestinal bleeding for dabigatran and warfarin. Among atrial fibrillation and non-atrial fibrillation sub-cohorts, more upper gastrointestinal than lower gastrointestinal bleeding events occurred. Overall, compared with warfarin, dabigatran showed no difference in risk of gastrointestinal bleeding in the cohorts with and without atrial fibrillation (table 3 ).

The marginal effects shown in figure 2 highlight the effects of dabigatran and age on the risk of gastrointestinal bleeding among patients with atrial fibrillation. The risk of dabigatran related gastrointestinal bleeding increased among atrial fibrillation patients such that in patients over 75 the expected hazard ratio for gastrointestinal bleeding exceeded the risk with warfarin (dabigatran: hazard ratio $2.49,95 \%$ confidence interval 1.61 to 3.83; warfarin: $1.62,1.02$ to 2.58 ). Among patients without atrial fibrillation (supplemental figure A5 in appendix) aged 76 years and older, dabigatran related gastrointestinal bleeding was comparable to warfarin related gastrointestinal bleeding (dabigatran: hazard ratio $1.56,0.42$ to 5.80 ; warfarin: $2.73,0.83$ to 8.94 ). 


\begin{tabular}{|c|c|c|c|c|c|c|}
\hline \multirow[b]{2}{*}{ Characteristics } & \multicolumn{3}{|l|}{ Full cohort } & \multicolumn{3}{|c|}{ Propensity matched cohort } \\
\hline & $\begin{array}{l}\text { Dabigatran } \\
(\mathrm{n}=7846)\end{array}$ & $\begin{array}{l}\text { Warfarin } \\
(n=22787)\end{array}$ & $P$ value & $\begin{array}{l}\text { Dabigatran } \\
(\mathrm{n}=7749)\end{array}$ & $\begin{array}{l}\text { Warfarin } \\
(\mathrm{n}=7749)\end{array}$ & $P$ value \\
\hline \multicolumn{7}{|l|}{ Demographics and risk scores } \\
\hline Mean (SD) age, years & $67.0(11.3)$ & $72.2(9.9)$ & $<0.01$ & $67.2(11.2)$ & $67.5(11.2)$ & $<0.01$ \\
\hline \multicolumn{7}{|l|}{ Age group, years: } \\
\hline $18-64$ & $3136(40.0)$ & 4479 (19.7) & \multirow{3}{*}{$-<0.01$} & 3039 (39.2) & $3046(39.3)$ & \multirow{3}{*}{0.07} \\
\hline $65-75$ & $2647(33.7)$ & $8108(35.6)$ & & $2647(34.2)$ & $2635(34.0)$ & \\
\hline$\geq 76$ & $2063(26.3)$ & $10200(44.8)$ & & $2063(26.6)$ & $2068(26.7)$ & \\
\hline Female sex & $2791(35.6)$ & $9618(42.2)$ & $<0.01$ & $2782(35.9)$ & $2769(35.7)$ & 0.78 \\
\hline \multicolumn{7}{|l|}{ Race/ethnicity: } \\
\hline White & $6036(76.9)$ & $17830(78.2)$ & \multirow{3}{*}{$-<0.01$} & $5969(77.0)$ & $5997(77.4)$ & \multirow{3}{*}{0.88} \\
\hline Black & $657(8.4)$ & $2168(9.5)$ & & $652(8.4)$ & $654(8.4)$ & \\
\hline Other & $1153(14.7)$ & $2789(12.2)$ & & $1128(14.6)$ & $1098(14.2)$ & \\
\hline \multicolumn{7}{|l|}{ Charlson-Deyo index: } \\
\hline $0-1$ & $4327(55.1)$ & $9233(40.5)$ & \multirow[t]{2}{*}{$<0.01$} & $4234(54.6)$ & $4231(54.6)$ & \multirow[t]{2}{*}{0.95} \\
\hline$\geq 2$ & $3519(44.9)$ & $13554(59.5)$ & & $3515(45.4)$ & $3518(45.4)$ & \\
\hline \multicolumn{7}{|l|}{ CHADS2 score: } \\
\hline $0-1$ & $3605(45.9)$ & $6,820(29.9)$ & \multirow[t]{2}{*}{$<0.01$} & $3518(45.4)$ & $3470(44.8)$ & \multirow[t]{2}{*}{0.27} \\
\hline$\geq 2$ & $4241(54.1)$ & $15967(70.1)$ & & $4231(54.6)$ & $4279(55.2)$ & \\
\hline \multicolumn{7}{|l|}{ HAS-BLED score: } \\
\hline $0-2$ & $5604(71.4)$ & $14075(61.8)$ & \multirow{3}{*}{$-<0.01$} & $5514(71.2)$ & $5534(71.4)$ & \multirow{3}{*}{0.90} \\
\hline 3 & $1677(21.4)$ & $6301(27.7)$ & & $1670(21.6)$ & $1663(21.5)$ & \\
\hline$\geq 4$ & $565(7.2)$ & $2411(10.6)$ & & $565(7.3)$ & $552(7.1)$ & \\
\hline \multicolumn{7}{|l|}{ Baseline comorbidities } \\
\hline Myocardial infarction & $531(6.8)$ & $2290(10.0)$ & $<0.01$ & $531(6.9)$ & $482(6.2)$ & 0.09 \\
\hline CABG/PCI & $361(4.6)$ & $1443(6.3)$ & $<0.01$ & $361(4.7)$ & $327(4.2)$ & 0.17 \\
\hline Congestive heart failure & $1913(24.4)$ & $7783(34.2)$ & $<0.01$ & $1912(24.7)$ & $1915(24.7)$ & 0.94 \\
\hline Diabetes & $2256(28.8)$ & $7802(34.2)$ & $<0.01$ & $2249(29.0)$ & $2274(29.3)$ & 0.59 \\
\hline History of gastrointestinal bleed: & $59(0.8)$ & $325(1.4)$ & $<0.01$ & $59(0.8)$ & $49(0.6)$ & 0.33 \\
\hline Upper gastrointestinal bleed & $39(0.5)$ & $200(0.9)$ & $<0.01$ & $39(0.5)$ & $31(0.4)$ & 0.33 \\
\hline Lower gastrointestinal bleed & $20(0.3)$ & $125(0.5)$ & $<0.01$ & $20(0.3)$ & $18(0.2)$ & 0.75 \\
\hline Helicobacter pylori & $31(0.4)$ & $89(0.4)$ & 0.96 & $31(0.4)$ & $29(0.4)$ & 0.80 \\
\hline Diverticulosis & $605(7.7)$ & $1973(8.7)$ & $<0.01$ & $599(7.7)$ & $571(7.4)$ & 0.36 \\
\hline Renal disease & $600(7.6)$ & $3455(15.2)$ & $<0.01$ & $600(7.7)$ & $617(8.0)$ & 0.54 \\
\hline \multicolumn{7}{|l|}{ Concomitant drug exposure } \\
\hline Inhibitors of warfarin* & $5560(70.9)$ & $15809(69.4)$ & 0.01 & $5484(70.8)$ & $5490(70.8)$ & 0.89 \\
\hline Inducers of warfarin* & $2287(29.1)$ & $7530(33.0)$ & $<0.01$ & $2263(29.2)$ & $2185(28.2)$ & 0.11 \\
\hline Antiplatelet agents & $991(12.6)$ & $3150(13.8)$ & $<0.01$ & $983(12.7)$ & $930(12.0)$ & 0.16 \\
\hline Non-steroidal anti-inflammatory drugs & $1764(22.5)$ & $4567(20.0)$ & $<0.01$ & $1734(22.4)$ & $1702(22.0)$ & 0.47 \\
\hline Selective serotonin reuptake inhibitors & 1107 (14.1) & $3304(14.5)$ & 0.40 & $1096(14.1)$ & $1055(13.6)$ & 0.28 \\
\hline Proton pump inhibitors & $1738(22.2)$ & $5747(25.2)$ & $<0.01$ & $1723(22.2)$ & $1655(21.4)$ & 0.13 \\
\hline Glucocorticoids & $1428(18.2)$ & $4835(21.2)$ & $<0.01$ & $1415(18.3)$ & $1404(18.1)$ & 0.79 \\
\hline
\end{tabular}

\section{Risk of gastrointestinal bleeding with rivaroxaban} compared with warfarin

To create the atrial fibrillation cohort, we matched 95\% of the rivaroxaban patients to $22.7 \%$ of the warfarin patients to create 5166 matched pairs (table 4). To create the non-atrial fibrillation cohort, we matched 99.9\% of patients prescribed rivaroxaban to $23.9 \%$ of those prescribed warfarin to create 10803 matched pairs (table 5). We compared patients' demographics and clinical characteristics between rivaroxaban and warfarin cohorts both with and without atrial fibrillation. Patients with atrial fibrillation were not statistically different, and characteristics of non-atrial fibrillation patients that were statistically different $(\mathrm{P}<0.05)$ were controlled for in the hazard ratio model.

Table 3 shows the incidence rates for total, upper, and lower gastrointestinal bleeding for rivaroxaban and warfarin. Among patients with and without atrial fibrillation who were prescribed rivaroxaban, we observed similar rates of gastrointestinal bleeding compared with matched patients prescribed warfarin. A pattern of elevation of risk of gastrointestinal bleeding with advancing age (similar to that with dabigatran) was observed in patients prescribed rivaroxaban (compared with warfarin). As shown in figure 3, by age 76 and over the risk of rivaroxaban related gastrointestinal bleeding 
Table 2 | Characteristics of non-atrial fibrillation patients by drug exposure: dabigatran propensity score 1:1 match. Values are numbers (percentages) unless stated otherwise

\begin{tabular}{|c|c|c|c|c|c|c|}
\hline \multirow[b]{2}{*}{ Characteristics } & \multicolumn{3}{|l|}{ Full cohort } & \multicolumn{3}{|c|}{ Propensity matched cohort } \\
\hline & $\begin{array}{l}\text { Dabigatran } \\
(n=732)\end{array}$ & $\begin{array}{l}\text { Warfarin } \\
(n=45198)\end{array}$ & P value & $\begin{array}{l}\text { Dabigatran } \\
(n=732)\end{array}$ & $\begin{array}{l}\text { Warfarin } \\
(n=732)\end{array}$ & P value \\
\hline \multicolumn{7}{|l|}{ Demographics and risk scores } \\
\hline Mean (SD) age, years & $64.6(12.9)$ & $61.9(13.7)$ & $<0.01$ & $64.6(12.9)$ & $63.1(14.1)$ & $<0.01$ \\
\hline \multicolumn{7}{|l|}{ Age, years: } \\
\hline $18-64$ & $358(48.9)$ & $24172(53.5)$ & \multirow{3}{*}{$<0.01$} & $358(48.9)$ & $369(50.4)$ & \multirow{3}{*}{0.54} \\
\hline $65-75$ & $202(27.6)$ & $13445(29.7)$ & & $202(27.6)$ & $202(27.6)$ & \\
\hline$\geq 76$ & $172(23.5)$ & $7581(16.8)$ & & $172(23.5)$ & $161(22.0)$ & \\
\hline Female & $272(37.2)$ & $23500(52.0)$ & $<0.01$ & $272(37.2)$ & $269(36.7)$ & 0.81 \\
\hline \multicolumn{6}{|l|}{ Race/ethnicity: } & \multirow{4}{*}{0.42} \\
\hline White & $499(68.2)$ & $33907(75.0)$ & & $499(68.2)$ & $521(71.2)$ & \\
\hline Black & $82(11.2)$ & $5343(11.8)$ & $<0.01$ & $82(11.2)$ & $72(9.8)$ & \\
\hline Other & $151(20.6)$ & $5948(13.2)$ & & $151(20.6)$ & $139(19.0)$ & \\
\hline \multicolumn{6}{|l|}{ Charlson-Deyo index: } & \multirow{3}{*}{0.38} \\
\hline $0-1$ & $413(56.4)$ & $26370(58.3)$ & 0.30 & $413(56.4)$ & $425(58.1)$ & \\
\hline$\geq 2$ & $319(43.6)$ & $18828(41.7)$ & & $319(43.6)$ & $307(41.9)$ & \\
\hline \multicolumn{6}{|l|}{ HAS-BLED score: } & \multirow{4}{*}{0.32} \\
\hline $0-2$ & $564(77.0)$ & $33857(74.9)$ & & $564(77.0)$ & $578(79.0)$ & \\
\hline 3 & $118(16.1)$ & 8501 (18.8) & 0.17 & $118(16.1)$ & $114(15.6)$ & \\
\hline$\geq 4$ & $50(6.8)$ & $2840(6.3)$ & & $50(6.8)$ & $40(5.5)$ & \\
\hline \multicolumn{7}{|l|}{ Baseline comorbidities } \\
\hline Myocardial infarction & $69(9.4)$ & $2492(5.5)$ & $<0.01$ & $69(9.4)$ & $78(10.7)$ & 0.37 \\
\hline $\mathrm{CABG} / \mathrm{PCl}$ & $35(4.8)$ & $1004(2.2)$ & $<0.01$ & $35(4.8)$ & $43(5.9)$ & 0.29 \\
\hline Congestive heart failure & $141(19.3)$ & $4635(10.3)$ & $<0.01$ & $141(19.3)$ & $147(20.1)$ & 0.61 \\
\hline Diabetes & $209(28.6)$ & $10322(22.8)$ & $<0.01$ & $209(28.6)$ & $190(26.0)$ & 0.15 \\
\hline History of gastrointestinal bleed: & $3(0.4)$ & $499(1.1)$ & 0.07 & $3(0.4)$ & $8(1.1)$ & 0.10 \\
\hline Upper gastrointestinal bleed & $3(0.4)$ & $316(0.7)$ & 0.35 & $3(0.4)$ & $7(1.0)$ & 0.16 \\
\hline Lower gastrointestinal bleed & $0(0.0)$ & $183(0.4)$ & 0.08 & $0(0.0)$ & $1(0.1)$ & - \\
\hline Helicobacter pylori & $2(0.3)$ & $194(0.4)$ & 0.52 & $2(0.3)$ & $1(0.1)$ & 0.56 \\
\hline Diverticulosis & $52(7.1)$ & $3645(8.1)$ & 0.34 & $52(7.1)$ & $35(4.8)$ & 0.05 \\
\hline Renal disease & $49(6.7)$ & $3742(8.3)$ & 0.12 & $49(6.7)$ & $44(6.0)$ & 0.56 \\
\hline \multicolumn{7}{|l|}{ Concomitant drug exposure } \\
\hline Inhibitors of warfarin* & $457(62.4)$ & $24591(54.4)$ & $<0.01$ & $457(62.4)$ & $461(63.0)$ & 0.73 \\
\hline Inducers of warfarin* & $205(28.0)$ & $15192(33.6)$ & $<0.01$ & $205(28.0)$ & $196(26.8)$ & 0.49 \\
\hline Antiplatelet agents & $128(17.5)$ & $3418(7.6)$ & $<0.01$ & $128(17.5)$ & $137(18.7)$ & 0.44 \\
\hline Non-steroidal anti-inflammatory drugs & $162(22.1)$ & $16408(36.3)$ & $<0.01$ & $162(22.1)$ & $159(21.7)$ & 0.79 \\
\hline Selective serotonin reuptake inhibitors & $118(16.1)$ & $9002(19.9)$ & 0.01 & $118(16.1)$ & $127(17.3)$ & 0.41 \\
\hline Proton pump inhibitors & $165(22.5)$ & $11290(25.0)$ & 0.13 & $165(22.5)$ & $159(21.7)$ & 0.64 \\
\hline Glucocorticoids & $130(17.8)$ & $11377(25.2)$ & $<0.01$ & 130 (17.8) & $125(17.1)$ & 0.66 \\
\hline
\end{tabular}

\section{Table 3 | Events and adjusted hazards of gastrointestinal bleeding}

\begin{tabular}{|c|c|c|c|c|c|c|}
\hline & \multicolumn{2}{|c|}{ Events per 100 patient years $(95 \% \mathrm{Cl})$} & \multirow{2}{*}{$\begin{array}{l}\text { Hazard ratio* }(95 \% \mathrm{Cl}) \\
\text { for bleeding: } \\
\text { dabigatran } v \text { warfarin }\end{array}$} & \multicolumn{2}{|c|}{ Events per 100 patient years $(95 \% \mathrm{Cl})$} & \multirow{2}{*}{$\begin{array}{l}\text { Hazard ratio* }(95 \% \mathrm{Cl}) \\
\text { for bleeding: } \\
\text { rivaroxaban } v \text { warfarir }\end{array}$} \\
\hline & Dabigatran & Warfarin & & Rivaroxaban & Warfarin & \\
\hline \multicolumn{7}{|l|}{ Atrial fibrillation } \\
\hline Total bleeding events & 2.29 (1.88 to 2.79$)$ & 2.87 (2.41 to 3.41) & 0.79 (0.61 to1.03) & 2.84 (2.30 to 3.52$)$ & 3.06 (2.49 to 3.77$)$ & $0.93(0.69$ to 1.25$)$ \\
\hline Upper GI bleeding events & $1.42(1.11$ to 1.83$)$ & 1.81 (1.45 to 2.25$)$ & 0.78 (0.56 to 1.09$)$ & $1.83(1.40$ to 2.39$)$ & 1.74 (1.32 to 2.28$)$ & $1.05(0.72$ to 1.54$)$ \\
\hline Lower GI bleeding events & 0.86 (0.63 to 1.19$)$ & $1.06(0.80$ to 1.41$)$ & $0.81(0.53$ to 1.24$)$ & 1.02 (0.97 to1.82) & 1.33 (0.97 to 1.82) & $0.77(0.48,1.24)$ \\
\hline \multicolumn{7}{|l|}{ Non-atrial fibrillation } \\
\hline Total bleeding events & $4.10(2.47$ to 6.80$)$ & $3.71(2.16$ to 6.40$)$ & $1.14(0.54$ to 2.39$)$ & 1.66 (1.23 to 2.24$)$ & 1.57 (1.25 to 1.99) & $0.89(0.60$ to 1.32$)$ \\
\hline Upper GI bleeding events & 2.73 (1.47 to 5.08$)$ & $2.57(1.34$ to 4.94$)$ & 1.09 (0.44 to 2.69$)$ & $1.03(0.70$ to 1.51$)$ & $0.99(0.74$ to 1.33$)$ & $0.87(0.53$ to 1.44$)$ \\
\hline Lower GI bleeding events & 1.37 (0.57 to 3.28$)$ & 1.14 (0.43 to 3.04$)$ & $1.23(0.33$ to 4.59$)$ & $0.63(0.39$ to 1.03$)$ & $0.58(0.40$ to 0.86$)$ & $0.91(0.48$ to 1.73$)$ \\
\hline
\end{tabular}




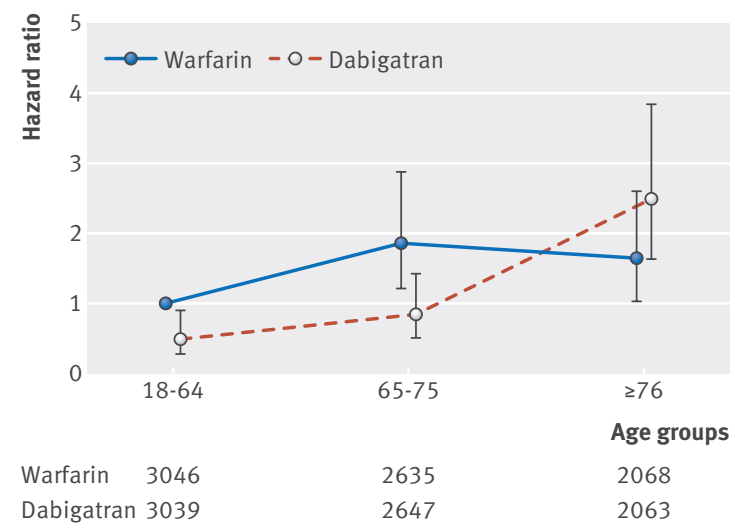

Fig 2 Dabigatran versus warfarin in patients with atrial fibrillation: treatment effect by age

among atrial fibrillation patients (hazard ratio 2.91, 1.65 to 4.81) exceeded the risk with warfarin in the same age category (2.05, 1.17 to 3.59). Among non-atrial fibrillation patients over 75 , we saw a similar increase in risk of rivaroxaban related gastrointestinal bleeding (hazard ratio 4.58, 2.40 to 8.72 ) compared with warfarin (4.40, 2.43 to 7.96 ) (see supplemental figure A6 in appendix).

Risk of cerebrovascular accident with dabigatran, rivaroxaban, and warfarin

Both dabigatran and rivaroxaban showed similar event rates to warfarin for the prevention of stroke (see table A4 in appendix); the event rates were not statistically different.

\section{Discussion}

Using administrative claims data representing a broad sample of privately insured people in the United States, we found that rates of gastrointestinal bleeding among patients treated with the novel oral anticoagulants dabigatran and rivaroxaban were similar to those observed among patients treated with warfarin. In both patients with and those without atrial fibrillation, the rates of gastrointestinal bleeding were similar between those treated with rivaroxaban or dabigatran and warfarin. Rate of bleeding increased at a greater rate with age among patients treated with novel oral anticoagulants compared with warfarin. Our data were also consistent with published trial data showing non-inferiority of dabigatran and rivaroxaban to warfarin for prevention of cerebrovascular accident. ${ }^{18} 19$

\section{Interpretation of findings}

Previous meta-analyses of randomized trials examining rates of gastrointestinal bleeding for dabigatran and rivaroxaban, compared with warfarin, have identified higher rates of bleeds for the novel oral anticoagulants. ${ }^{9} 20$ However, there has been very little real world assessment of the safety of novel oral anticoagulants, which have had rapid uptake into routine care. ${ }^{7}$ Much of the focus has been on dabigatran, and many of the analyses have solely focused on Medicare populations. In our analyses, we were able to evaluate the safety of both dabigatran and rivaroxaban in a diverse population that included people of all ages. The rates of use for non-atrial fibrillation indications tend to be much greater in the younger populations and are predominantly for rivaroxaban ( $<65$ years old), whereas rates of use for atrial fibrillation are much greater in the older population for both of the novel oral anticoagulants (see tables 1 and 4).

The differences in rates of gastrointestinal bleeding might be attributable to patients receiving novel oral anticoagulants differing from those that were enrolled in the trials. For example, the mean age of the participants in the RE-LY trial was 71.5 years compared with 67.2 years for those with atrial fibrillation in our study. ${ }^{19}$ Similarly, patients enrolled in ROCKET-AF had a median age of 73 compared with the mean age of 69.0 for those receiving rivaroxaban for atrial fibrillation in our study. ${ }^{18}$ Furthermore, only a third of the RE-LY cohort had a $\mathrm{CHADS}_{2}$ score of $0-1$ and none of the ROCKET-AF cohort had a $\mathrm{CHADS}_{2}$ score of 0-1, whereas more than $40 \%$ of those receiving dabigatran or rivaroxaban for atrial fibrillation in our cohort had a $\mathrm{CHADS}_{2}$ score of 0-1.

\section{Implications for healthcare professionals and patients}

The increasing availability of options for anticoagulation provides benefits and challenges for both healthcare professionals and patients. Although the increasing number of options has provided choices for patients and providers, much less clarity exists regarding which patients are most likely to benefit from the newer agents and who may be at greatest risk. This study suggests that, in general, patients younger than 65 have fewer gastrointestinal bleeding events when treated with novel anticoagulants; however, the risk of this adverse event increases over the age of 65 and is particularly concerning for those over 75 . These higher rates of bleeding with age are consistent with those seen in recently published studies evaluating efficacy and safety of dabigatran by Graham and Hernandez, ${ }^{21} 22$ as well as in the meta-analysis by Eikelboom. ${ }^{23}$ However, none of those studies specifically included the rates of bleeding for patients under the age of 65 . A closer assessment of the risks and benefits may be necessary for older patients. Several other factors may also reasonably affect treatment choices, such as the cost of therapy, patients' and providers' ability to manage the testing requirements of warfarin, and the potential for drug-drug interactions.

\section{Strengths and weaknesses of study}

Our study had some weaknesses and important limitations. Firstly, our analysis was limited to the novel oral anticoagulants for which enough data were available (dabigatran and rivaroxaban). We were not able to assess apixaban owing to the limited number of patients prescribed this drug in our dataset during the period of observation. Secondly, we assessed the outcome and underlying risk by using administrative claims and the assessment may be susceptible to 


\begin{tabular}{|c|c|c|c|c|c|c|}
\hline \multirow[b]{2}{*}{ Characteristics } & \multicolumn{3}{|l|}{ Full cohort } & \multicolumn{3}{|c|}{ Propensity matched cohort } \\
\hline & $\begin{array}{l}\text { Rivaroxaban } \\
(\mathrm{n}=5434)\end{array}$ & $\begin{array}{l}\text { Warfarin } \\
(\mathrm{n}=22787)\end{array}$ & $P$ value & $\begin{array}{l}\text { Rivaroxaban } \\
(\mathrm{n}=5166)\end{array}$ & $\begin{array}{l}\text { Warfarin } \\
(\mathrm{n}=5166)\end{array}$ & $P$ value \\
\hline \multicolumn{7}{|l|}{ Demographics and risk scores } \\
\hline Mean (SD) age, years & $68.4(11.1)$ & $72.2(9.9)$ & $<0.01$ & $69.0(10.9)$ & $69.1(10.9)$ & 0.54 \\
\hline \multicolumn{7}{|l|}{ Age group, years: } \\
\hline $18-64$ & $1865(34.3)$ & $4479(19.7)$ & \multirow{3}{*}{$<0.01$} & $1608(31.1)$ & $1649(31.9)$ & \multirow{3}{*}{-0.37} \\
\hline $65-75$ & $1987(36.6)$ & $8,108(35.6)$ & & 1976 (38.3) & 1908 (36.9) & \\
\hline$\geq 76$ & $1582(29.1)$ & $10,200(44.8)$ & & $1582(30.6)$ & $1609(31.1)$ & \\
\hline Female sex & $2081(38.3)$ & $9,618(42.2)$ & $<0.01$ & 2016 (39.0) & $2000(38.7)$ & 0.69 \\
\hline \multicolumn{7}{|l|}{ Race/ethnicity: } \\
\hline White & $4220(77.7)$ & $17830(78.2)$ & \multirow{3}{*}{$<0.01$} & $4025(77.9)$ & $4047(78.3)$ & \multirow{3}{*}{0.62} \\
\hline Black & $436(8.0)$ & $2168(9.5)$ & & $423(8.2)$ & $431(8.3)$ & \\
\hline Other & $778(14.3)$ & $2789(12.2)$ & & 718 (13.9) & $688(13.3)$ & \\
\hline \multicolumn{3}{|l|}{ Charlson-Deyo index: } & \multicolumn{3}{|l|}{$<0.01$} & \multirow{3}{*}{0.41} \\
\hline $0-1$ & $2946(54.2)$ & $9233(40.5)$ & & $2702(52.3)$ & $2733(52.9)$ & \\
\hline$\geq 2$ & $2488(45.8)$ & $13554(59.5)$ & & $2464(47.7)$ & $2433(47.1)$ & \\
\hline \multicolumn{3}{|l|}{ CHADS2 score: } & \multirow{3}{*}{$<0.01$} & & & \multirow[t]{3}{*}{0.93} \\
\hline $0-1$ & $2391(44.0)$ & $6820(29.9)$ & & $2164(41.9)$ & $2167(41.9)$ & \\
\hline$\geq 2$ & $3043(56.0)$ & $15967(70.1)$ & & $3002(58.1)$ & $2999(58.1)$ & \\
\hline \multicolumn{6}{|l|}{ HAS-BLED score: } & \multirow{4}{*}{-0.58} \\
\hline $0-2$ & $3790(69.7)$ & $14075(61.8)$ & & $3541(68.5)$ & $3,585(69.4)$ & \\
\hline 3 & $1287(23.7)$ & $6301(27.7)$ & $<0.01$ & $1269(24.6)$ & $1,251(24.2)$ & \\
\hline$\geq 4$ & $357(6.6)$ & 2411 (10.6) & & $356(6.9)$ & $330(6.4)$ & \\
\hline \multicolumn{7}{|l|}{ Baseline comorbidities } \\
\hline Myocardial infarction & $382(7.0)$ & $2290(10.0)$ & $<0.01$ & $379(7.3)$ & $381(7.4)$ & 0.94 \\
\hline $\mathrm{CABG} / \mathrm{PCl}$ & $211(3.9)$ & $1443(6.3)$ & $<0.01$ & $211(4.1)$ & $217(4.2)$ & 0.76 \\
\hline Congestive heart failure & $1337(24.6)$ & $7783(34.2)$ & $<0.01$ & $1323(25.6)$ & $1269(24.6)$ & 0.14 \\
\hline Diabetes & $1575(29.0)$ & $7802(34.2)$ & $<0.01$ & $1544(29.9)$ & $1548(30.0)$ & 0.92 \\
\hline History of gastrointestinal bleed: & $47(0.9)$ & $325(1.4)$ & $<0.01$ & $47(0.9)$ & $33(0.6)$ & 0.12 \\
\hline Upper gastrointestinal bleed & $30(0.6)$ & $200(0.9)$ & 0.02 & $30(0.6)$ & $18(0.3)$ & 0.08 \\
\hline Lower gastrointestinal bleed & $17(0.3)$ & $125(0.5)$ & 0.03 & $17(0.3)$ & $15(0.3)$ & 0.72 \\
\hline Helicobacter pylori & $17(0.3)$ & $89(0.4)$ & 0.40 & $17(0.3)$ & $16(0.3)$ & 0.86 \\
\hline Diverticulosis & $394(7.3)$ & $1973(8.7)$ & $<0.01$ & $383(7.4)$ & $341(6.6)$ & 0.09 \\
\hline Renal disease & $461(8.5)$ & $3455(15.2)$ & $<0.01$ & $461(8.9)$ & $444(8.6)$ & 0.49 \\
\hline \multicolumn{7}{|l|}{ Concomitant drug exposure } \\
\hline Inhibitors of warfarin* & $3828(70.4)$ & $15809(69.4)$ & 0.12 & $3628(70.2)$ & $3638(70.4)$ & 0.78 \\
\hline Inducers of warfarin* & $1687(31.0)$ & $7530(33.0)$ & $<0.01$ & $1612(31.2)$ & $1555(30.1)$ & 0.16 \\
\hline Antiplatelet agents & $734(13.5)$ & $3150(13.8)$ & 0.54 & $698(13.5)$ & $690(13.4)$ & 0.81 \\
\hline Non-steroidal anti-inflammatory drugs & $1297(23.9)$ & $4567(20.0)$ & $<0.01$ & $1205(23.3)$ & $1185(22.9)$ & 0.59 \\
\hline Selective serotonin reuptake inhibitors & $782(14.4)$ & 3304 (14.5) & 0.84 & 744 (14.4) & 717 (13.9) & 0.40 \\
\hline Proton pump inhibitors & $1341(24.7)$ & $5747(25.2)$ & 0.41 & $1291(25.0)$ & $1207(23.4)$ & 0.03 \\
\hline Glucocorticoids & $1091(20.1)$ & $4835(21.2)$ & 0.06 & 1029 (19.9) & 997 (19.3) & 0.37 \\
\hline
\end{tabular}

variability in coding and billing practices. Thirdly, we tried to account for the selection bias related to treatment choice by using propensity score matching. However, this still leaves the possibility of unobserved confounding. Fourthly, our inability to capture over the counter aspirin use limits our examination of its effect on overall bleeding rates. However, we have included the influence of prescribed aspirin, and we have no reason to suspect a differential rate of use that would substantially affect bleeding rates among patients. In addition, we were not able to assess the relative rates of gastrointestinal bleeding for patients receiving a $110 \mathrm{mg}$ twice daily dose of dabigatran as this dose is not approved in the United States, although it is approved in Europe. This limits the generalizability of these results to patients in Europe receiving $150 \mathrm{mg}$ twice a day. Fifthly, we did a one to one propensity score matched analysis. We could have considered one to two propensity score matched analysis, which would have increased precision but potentially increased the bias. ${ }^{24} 25$ Finally, we focused primarily on an incident cohort of users, and the risk among a prevalent cohort or among patients who switched from warfarin to a novel oral anticoagulant might be different.

Despite these limitations, our investigation also had many strengths, including our inclusion of a diverse, real world population; follow-up that extended 


\begin{tabular}{|c|c|c|c|c|c|c|}
\hline Characteristics & \multicolumn{3}{|l|}{ Full cohort } & \multicolumn{3}{|c|}{ Propensity matched cohort } \\
\hline \multicolumn{7}{|l|}{ Demographics and risk scores } \\
\hline Mean (SD) age, years & $60.4(11.8)$ & $61.9(13.7)$ & $<0.01$ & $60.4(11.8)$ & $59.0(13.4)$ & $<0.01$ \\
\hline $18-64$ & $6903(63.8)$ & $24172(53.5)$ & \multirow{3}{*}{$<0.01$} & $6888(63.8)$ & $6920(64.1)$ & \multirow{3}{*}{-0.87} \\
\hline $65-75$ & $2916(27.0)$ & $13445(29.7)$ & & $2915(27.0)$ & $2887(26.7)$ & \\
\hline$\geq 76$ & $1000(9.2)$ & $7581(16.8)$ & & $1000(9.3)$ & $996(9.2)$ & \\
\hline Female sex & $6073(56.1)$ & $23500(52.0)$ & $<0.01$ & $6061(56.1)$ & $6084(56.3)$ & 0.60 \\
\hline \multicolumn{7}{|l|}{ Race/ethnicity: } \\
\hline \multicolumn{6}{|l|}{ Charlson-Deyo index: } & \multirow{3}{*}{$<0.01$} \\
\hline $0-1$ & $8075(74.6)$ & $26370(58.3)$ & $<0.01$ & $8059(74.6)$ & $8285(76.7)$ & \\
\hline$\geq 2$ & $2744(25.4)$ & $18828(41.7)$ & & $2744(25.4)$ & $2518(23.3)$ & \\
\hline \multicolumn{6}{|l|}{ HAS-BLED score: } & \multirow{4}{*}{-0.04} \\
\hline $0-2$ & $8623(79.7)$ & $33857(74.9)$ & \multirow{3}{*}{$<0.01$} & $8608(79.7)$ & $8709(80.6)$ & \\
\hline 3 & $1775(16.4)$ & $8501(18.8)$ & & $1774(16.4)$ & $1727(16.0)$ & \\
\hline$\geq 4$ & $421(3.9)$ & $2840(6.3)$ & & $421(3.9)$ & $367(3.4)$ & \\
\hline \multicolumn{7}{|l|}{ Baseline comorbidities } \\
\hline Myocardial infarction & $224(2.1)$ & $2492(5.5)$ & $<0.01$ & $224(2.1)$ & $161(1.5)$ & $<0.01$ \\
\hline $\mathrm{CABG} / \mathrm{PCl}$ & $72(0.7)$ & $1004(2.2)$ & $<0.01$ & $72(0.7)$ & $45(0.4)$ & $<0.01$ \\
\hline Diverticulosis & $695(6.4)$ & $3645(8.1)$ & $<0.01$ & $695(6.4)$ & $619(5.7)$ & 0.01 \\
\hline Renal disease & $461(4.3)$ & $3742(8.3)$ & $<0.01$ & $461(4.3)$ & $398(3.7)$ & 0.01 \\
\hline \multicolumn{7}{|l|}{ Concomitant drug exposure } \\
\hline Inhibitors of warfarin* & $5566(51.4)$ & $24591(54.4)$ & $<0.01$ & $5555(51.4)$ & $5578(51.6)$ & 0.60 \\
\hline Inducers of warfarin* & $3300(30.5)$ & $15192(33.6)$ & $<0.01$ & $3297(30.5)$ & $3192(29.5)$ & 0.02 \\
\hline Antiplatelet agents & $470(4.3)$ & $3418(7.6)$ & $<0.01$ & $470(4.4)$ & $366(3.4)$ & $<0.01$ \\
\hline Non-steroidal anti-inflammatory drugs & $5420(50.1)$ & $16408(36.3)$ & $<0.01$ & $5404(50.0)$ & $5316(49.2)$ & 0.03 \\
\hline Selective serotonin reuptake inhibitors & $2441(22.6)$ & 9002 (19.9) & $<0.01$ & $2428(22.5)$ & $2304(21.3)$ & $<0.01$ \\
\hline Proton pump inhibitors & $2398(22.2)$ & $11290(25.0)$ & $<0.01$ & $2397(22.2)$ & $2330(21.6)$ & 0.12 \\
\hline Glucocorticoids & $2549(23.6)$ & $11377(25.2)$ & $<0.01$ & $2547(23.6)$ & $2450(22.7)$ & 0.02 \\
\hline
\end{tabular}

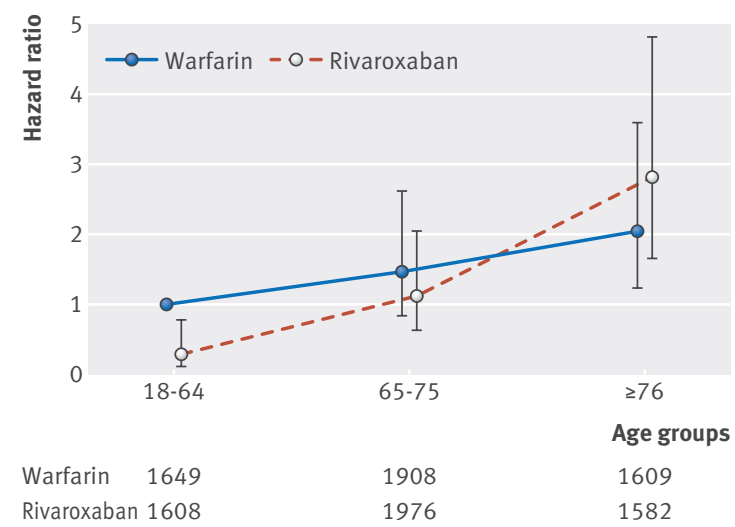

Fig 3 | Rivaroxaban versus warfarin patients with atrial fibrillation: treatment effect by age through 2013 with a large enough sample to examine both dabigatran and rivaroxaban; quantification of event rates for upper, lower, and total gastrointestinal bleeding; and assessment of the gastrointestinal bleeding profile of different novel oral anticoagulants by age, thus highlighting important safety concerns among older adults.

\section{Conclusions}

Our study is one of the first to evaluate the gastrointestinal safety of novel oral anticoagulants compared with warfarin and provides evidence to facilitate risk-benefit consideration of all treatment options by patients and providers. These data suggest the general safety of novel oral anticoagulants for the younger population but highlight potential gastrointestinal safety concerns among older people. 
Contributors: NSA, SS, and NDS were involved in the study concept and design. NDS, NSA, LRH, and HH were involved in the acquisition and analysis of data. All authors were involved in interpretation of data. NSA, NDS, HH, and LRH drafted the manuscript, and all authors critically revised it for important intellectual content. NDS, LRH, and HH did the statistical analysis. NSA and NDS supervised the study. NSA and NDS are the guarantors.

Funding: This study was funded by the Mayo Clinic Robert D and Patricia E Kern Center for the Science of Health Care Delivery.

Competing interests: All authors have completed the ICMJE uniform disclosure form at www.icmje.org/coi_disclosure.pdf (available on request from the corresponding author) and declare: GCA is chair of the FDA's Peripheral and Central Nervous System Advisory Committee, serves as a paid consultant to IMS Health, and serves on an IMS Health scientific advisory board; this arrangement has been reviewed and approved by Johns Hopkins University in accordance with its conflict of interest policies; no other relationships or activities that could appear to have influenced the submitted work.

Ethical approval: All study data were accessed using techniques compliant with the Health Insurance Portability and Accountability Act of 1996 (HIPAA), and, because this study involved analysis of pre-existing, de-identified data, it was exempt from institutional review board approval.

Transparency: The lead authors (the manuscript's guarantors) affirm that the manuscript is an honest, accurate, and transparent account of the study being reported; that no important aspects of the study have been omitted; and that any discrepancies from the study as planned (and, if relevant, registered) have been explained.

Data sharing: No additional data available.

This is an Open Access article distributed in accordance with the Creative Commons Attribution Non Commercial (CC BY-NC 4.0) license, which permits others to distribute, remix, adapt, build upon this work non-commercially, and license their derivative works on different terms, provided the original work is properly cited and the use is non-commercial. See: http://creativecommons.org/licenses/ by-nc/4.0/

1 Freedman JE, Gersh BJ. Atrial fibrillation and stroke prevention in aging patients: what's good can be even better. Circulation 2014;130:129-31

2 Wolf PA, Abbott RD, Kannel WB. Atrial fibrillation: a major contributor to stroke in the elderly: the Framingham Study. Arch Intern Med 1987;147:1561-4.

3 Chugh SS, Havmoeller R, Narayanan K, et al. Worldwide epidemiology of atrial fibrillation: a Global Burden of Disease 2010 Study. Circulation 2014;129:837-47.

4 Go AS, Hylek EM, Phillips KA, et al. Prevalence of diagnosed atrial fibrillation in adults: national implications for rhythm management and stroke prevention: the AnTicoagulation and Risk Factors in Atrial Fibrillation (ATRIA) Study. JAMA 2001:285:2370-5.

5 Hart RG, Pearce LA, Aguilar MI. Meta-analysis: antithrombotic therapy to prevent stroke in patients who have nonvalvular atrial fibrillation. Ann Intern Med 2007;146:857-67.

6 Abraham NS, Castillo DL. Novel anticoagulants: bleeding risk and management strategies. Curr Opin Gastroenterol 2013;29:676-83.

7 Kirley K, Qato DM, Kornfield R, et al. National trends in oral anticoagulant use in the United States, 2007 to 2011. Circ Cardiovas Qual Outcomes 2012;5:615-21.

8 Ruff CT, Giugliano RP, Braunwald E, et al. Comparison of the efficacy and safety of new oral anticoagulants with warfarin in patients with atrial fibrillation: a meta-analysis of randomised trials. Lancet 2014;383:955-62.

9 Holster IL, Valkhoff VE, Kuipers El, et al. New oral anticoagulants increase risk for gastrointestinal bleeding: a systematic review and meta-analysis. Gastroenterology 2013;145:105-12.

10 Halperin IL, Hankey GJ. Wojdyla DM, et al. Efficacy and safety of rivaroxaban compared with warfarin among elderly patients with nonvalvular atrial fibrillation in the Rivaroxaban Once Daily, Oral, Direct Factor Xa Inhibition Compared With Vitamin K Antagonism for Prevention of Stroke and Embolism Trial in Atrial Fibrillation (ROCKET AF). Circulation 2014;130:138-46.

11 Abraham NS, Hartman C, Richardson P, et al. Risk of lower and upper gastrointestinal bleeding, transfusions, and hospitalizations with complex antithrombotic therapy in elderly patients. Circulation 2013;128:1869-77.

12 Komocsi A, Vorobcsuk A, Kehl D, et al. Use of new-generation ora anticoagulant agents in patients receiving antiplatelet therapy after an acute coronary syndrome: systematic review and meta-analysis of randomized controlled trials. Arch Intern Med 2012;172:1537-45.

13 Goodman SG, Woidyla DM, Piccini IP, et al. Factors associated with major bleeding events: insights from the ROCKET AF trial (rivaroxaban once-daily oral direct factor Xa inhibition compared with vitamin $\mathrm{K}$ antagonism for prevention of stroke and embolism trial in atrial fibrillation). J Am Coll Cardiol 2014;63:891-900.

14 Wallace PJ, Shah ND, Dennen T, et al. Optum Labs: building a novel node in the learning health care system. Health Aff (Millwood) 2014:33:1187-94.

15 Deyo RA, Cherkin DC, Ciol MA. Adapting a clinical comorbidity index for use with ICD-9-CM administrative databases. / Clin Epidemiol 1992;45:613-9.

16 Tsadok MA, Jackevicius CA, Rahme E, et al. Sex differences in stroke risk among older patients with recently diagnosed atrial fibrillation. JAMA 2012;307:1952-8.

17 Pisters R, Lane DA, Nieuwlaat R, et al. A novel user-friendly score (HAS-BLED) to assess 1-year risk of major bleeding in patients with atrial fibrillation: the Euro Heart Survey. Chest 2010;138:1093-100.

18 Patel MR, Mahaffey KW, Garg I, et al. Rivaroxaban versus warfarin in nonvalvular atrial fibrillation. N Engl J Med 2011;365:883-91.

19 Connolly SJ, Ezekowitz MD, YusufS, et al. Dabigatran versus warfarin in patients with atrial fibrillation. N Engl J Med 2009;361:1139-51.

20 Miller CS, Grandi SM, Shimony A, et al. Meta-analysis of efficacy and safety of new oral anticoagulants (dabigatran, rivaroxaban, apixaban) versus warfarin in patients with atrial fibrillation. Am I Cardiol 2012:110:453-60.

21 Graham DJ, Reichman ME, Wernecke M, et al. Cardiovascular, bleeding, and mortality risks in elderly Medicare patients treated with dabigatran or warfarin for non-valvular atrial fibrillation. Circulation 2015;131:157-64.

22 Hernandez I, Baik SH, Pinera A, et al. Risk of bleeding with dabigatran in atrial fibrillation. JAMA Intern Med 2015;175:18-24.

23 Eikelboom IW, Wallentin L, Connolly SI, et al. Risk of bleeding with 2 doses of dabigatran compared with warfarin in older and younger patients with atrial fibrillation: an analysis of the randomized evaluation of long-term anticoagulant therapy (RE-LY) trial. Circulation 2011;123:2363-72

24 Austin PC. Statistical criteria for selecting the optimal number of untreated subjects matched to each treated subject when using many-to-one matching on the propensity score. Am J Epidemiol 2010;172:1092-7.

25 Rassen JA, Shelat AA, Myers J, et al. One-to-many propensity score matching in cohort studies. Pharmacoepidemiol Drug Saf 2012;21 (suppl 2):69-80.

(c) BMJ Publishing Group Ltd 2015 